\title{
Analisis Kebutuhan Bahasa Inggris Pramusaji di Hotel Berbintang 5 di Bali
}

\author{
Ni Luh Manda Wulandari, Putu Indah Rahmawati
}

\author{
Undiksha
}

\begin{abstract}
Abstrak
Penelitian ini bertujuan untuk menganalisa kebutuhan keterampilan serta fungsi dan ekspresi Bahasa Inggris yang dibutuhkan seorang pramusaji. Penelitian ini termasuk jenis penelitian deskriptif kualitatif, dengan metode wawancara dan dokumentasi dalam pengumpulan data. Subjek dalam penelitian ini adalah Asst. Manager F\&B Service, Manager Restoran, Supervisor, dan Staff Restoran Hotel Berbintang 5 di Bali. Hasil Penelitian ini menunjukkan bahwa (1) Speaking \& listening skill merupakan poin utama yang harus dikuasai seorang pramusaji, serta ketepatan (accurancy) grammar dan kelancaran (fluency) dalam berkomunikasi juga memegang peranan yang sama penting, (2) Ekspresi bahasa yang digunakan menyesuaikan dengan fungsi bahasa yang telah ditetapkan berdasarkan pelaksanaan Squence of Service (SOS) di restoran. Dari hasil penelitian ini mungkin dibutuhkannya penelitian lanjutan mengenai analisis kebutuhan Bahasa Inggris Pramusaji dalam ruang lingkup yang lebih luas.
\end{abstract}

Kata Kunci : analisis kebutuhan, keterampilan berbahas, fungsi dan ekspresi bahasa, dan pramusaji.

Abstract
This study aimed at analyzing the English language skills functions and expressions needed as a waiter/ss. This research was a qualitative descriptive. The method used in obtaining the required information were interviews and documentation, in which subjects in this research were Asst. F\&B Service Manager, Restaurant Manager, Supervisor, and Restaurant Staff in 5-Star Hotel in Bali. The results of this study indicated that (1) Speaking \& listening skills are the main poins that must be mastered by a waiter/ss, and the accuracy of grammar and fluency in communication also have an equally important role, (2) The expression of the language used adjusts to predetermined language functions based on the implementation of Sequence of Service (SOS) in restaurants. From the results of this study it may be necessary to further research on analyzing the needs of English Waiters in a broader scope.

Keywords: analysis of needs, language skills, language functions and expressions, waiters.

\section{Pendahuluan}

Kebutuhan akan tenaga kerja yang terampil dalam memberikan pelayanan yang optimal sangatlah diperlukan dalam industri pariwisata khususnya industri perhotelan. Menteri Pendidikan dan Kebudayaan (Efendy, 2018) menyampaikan bahwa keterampilan berkomunikasi merupakan salah satu modal yang dibutuhkan peserta didik untuk memasuki abad 21 dan menguasai revolusi industri 4.0. Keterampilan komunikasi merupakan salah satu hal yang dibutuhkan dan harus dikuasai khususnya di dunia perhotelan. Dengan memiliki keterampilan berbahasa asing (khususnya Bahasa Inggis), mengingat Bahasa Inggris sebagai Bahasa Internasional akan mampu menghasilkan kinerja yang optimal. Al-saadi (dalam Damayanti, 2019), menyatakan bahwa keterampilan berahasa Inggris dapat meningkatkan efektifitas komunikasi antara pelaku wisata dengan wisatawan serta komunikasi antar pelaku wisata. Selain itu perkembangan dunia pendidikan juga menuntut akan adanya kesesuaian antara sistem pendidikan dengan kebutuhan dunia usaha atau dunia industri. Salah satu strategi yang bisa dilaksanakan dalam implementasi relevansi pendidikan dengan dunia kerja adalah melakukan "link and match" (Tynjälä, dalam 
Mahfud, dkk., 2017). Salah satu strategi dalam melakukan link and match adalah dengan melakukan analisa kebutuhan target.

Analisa kebutuhan target sangat diperlukan dalam departemen Tata Hidang (Food and Beverage Service). William and Swales (dalam Mahardika, 2019) memandang analis kebutuhan sebagai target-centered' untuk mengetahui tugas yang akan dilaksanakan di lapangan, sehingga dengan menspesifikasikan keterampilan, fungsi dan ekpresi bahasa apa yang diperlukan siswa dapat membantu pelaksanaan pekerjaan dengan baik.Savignon (1983, dalam Mahardika, 2019) lebih lanjut menyatakan bahwa mengerti serta menguasai penggunaan fungsi dan ekspresi sangat mempengaruhi kesuksesan dalam berkomunikasi Jadi dengan memiliki keterampilan berbahasa, pelayanan yang baik akan lebih mudah diberikan.Melihat adanya kebutuhan untuk melakukan sebuah analisa kebutuhan target penelitian ini kemudian direncanakan. Penelitian ini bertujuan untuk menganalisis kebutuhan Bahasa Inggris bagi Pramusaji di Hotel Berbintang 5 di Bali.

Berdasarkan latar belakang penelitian yang telah dipaparkan, maka penelitian ini bertujuan untuk menganalisa keterampilan Bahasa Inggris dan fungsi dan ekspresi Bahasa Inggris yang dibutuhkan sebagai seorang pramusaji.

\section{Kajian Pustaka}

\section{Definisi Konsep Analisis Kebutuhan}

Menurut Marrison (2001, dalam Alfiriani, dkk., 2017:2), analisis kebutuhan merupakan suatau cara untuk mengidentifikasikan masalah dalam menentukan tindakan yang tepat. Richards (2001, dalam Puspitasari, 2013:4) mendefinisikan analisis kebutuhan merupakan prosedur yang digunakan untuk menentukan kebutuhan peserta didik.

Lebih lanjut menurut menurut William and Swales (dalam Mahardika, 2019:2) memandang analis kebutuhan sebagai target-centered' untuk mengetahui tugas yang akan dilaksanakan di lapangan, sehingga dengan menspesifikasikan keterampilan, fungsi dan ekpresi bahasa apa yang diperlukan siswa dapat membantu pelaksanaan pekerjaan dengan baik.

Berdasarkan pendapat para ahli, dapat disimpulkan bahwa analisis kebutuhan merupakan suatu proses dalam menentukan kebutuhan berbahasa yang dibutuhkan peserta didik sesuai dengan target yang inginkan dalam pelaksanaan pekerjaan (Alfiriani, dkk., 2017; Mahardika, 2019; Puspitasari, 2013)

\section{Definisi Fungsi dan Ekspresi Bahasa}

Menurut Halliday dan Hassan (dalam Sulasmini dan Astina, 2018:4) mendefinisikan fungsi bahasa sebagai cara dalam berkata, menulis, membaca, dan mendengar untuk mencapai target tujuan. Lebih lanjut menurut Van Ek (1977, dalam Mahardika, 2019:2), bahwa ekspresi bahasa merupakan perbuatan yang diungkapkan berdasarkan konteks yang tepat untuk suatu fungsi tertentu" 
Savignon (1983, dalam Mahardika, 2019), bahwa mengerti serta menguasai penggunaan fungsi dan ekspresi bahasa sangat mempengaruhi kesuksesan dalam berkomunikasi. Lebih lanjut menurut Vestergaard dan Schroder (dalam Fernandez 2008:4), bahwa fungsi bahasa digunakan untuk menyalurkan ekspresi (berupa emosi, keinginan, dan perasaan) serta menyampaikan pesan (komunikator).

Berdasarkan pendapat para ahli, dapat disimpulkan bahwa mengerti dan menguasai fungsi dan ekspresi bahasa dapat menjamin kesuksesan dalam berkomunikasi karena ungkapkan ekspresi (berupa emosi, perasaan, dan keinginan) dapat disalurkan melalui fungsi dan ekspresi bahasa (Fernandez 2008; Mahardika, 2019; Sulasmini dan Astina, 2018).

\section{Konsep Tata Hidang (Food and Beverage Service)}

Tata Hidang (Food and Beverage Service ) merupakan salah satu departemen yang berperan penting dalam mendatangkan keuntungan bagi hotel, dimana Tata Hidang bertugas dan bertanggung jawab untuk menyiapkan dan menghidangkan makanan dan minuman kepada tamu yang disertakan dengan pelayanan yang baik (Redjasa, 2014; Utama, 2014; Wahyuningsih, 2019). Sedangkan restoran merupakan suatu bangunan yang dikelola secara komersial dan tak terbatas yang dapat melayani kebtuhan makanan dan minuman kepada pengunjung yang tinggalnya dekat maupun jauh (Juita, 2017; Wahyuningsih, 2019).

Pramusaji adalah karyawan atau karyawati pada sebuah restoran yang bertugas dan bertanggung jawab memberikan pelayanan kepada tamu secara profesional, mulai dari memberikan sambutan, menyiapkan meja dan peralatan makan, menyajikan makanan dan minuman, membantu memenuhi kebutuhan tamu, serta menjaga lingkungan restoran tetap bersih (Sugiarto (dalam AS dan Atalina, 2016); Suardana dan Nurhayati, 2019; Marsum (dalam Guntur dan Yulianto, 2015); Soekresno dan Pendit, 199). Lebih lanjut MenurutMarsum (2005:91) kriteria seeorang pramusaji yang baik yaitu mempunyai kesadaran social yang tinggi, karakter dan kepribadian yang baik, dan mampu berkomunikasi dengan baik dengan tamu.

Keterampilan merupakan suatu kemampuan dalam mengimplementasikan tugas atau pekerjaan secara efektif dan efisien (Dunette, 1976; Iverson, 2001; Gordon, 1994). Lebih lanjut Robbins (2000) menyatakan keterampilan ini klasifikasikan menjadi 4 katergori, yakni kemampuan dasar, teknik, interpersonal, dan problem solving. Dalam kaitannya dengan industry perhotelan Interpersonal Skillyang dimaksud yaitu menguasai keterampilan berbahasa agar mampu menjalin komunikasi yang baik dengan tamu. Menurut Tarigan (2015:2) ada 4 jenis keterampilan berbahasa berbicara (Speaking), mendengarkan (Listening), menulis (Writing), dan membaca (Reading). Dengan menguasai keterampilan berbahasa seorang pelaku perhotelan khususnya pramusaji akan lebih mudah bekerja. 


\section{Konsep Standard Operational Procedure (SOP)}

Menurut Soemohadiwidjojo (2004) Standar Operasional Prosedur (SOP) adalah panduan yang digunakan untuk memastikan kegiatan operasional organisasi atau perusahaan berjalan dengan konsisten, efektif, efisien, sistematis dan terkelola dengan baik. Sedangkan Menurut Budiharjo (2014) Standar Operasional Prosedur (SOP) adalah tahapan suatu proses kerja atau prosedur kerja tertentu yang bersifat rutin, tetap dan tidak berubah-ubah yang dibakukan kedalam sebuah dokumen tertulis.

Pengertian mengenai Standar Operasional Prosedur (SOP) yang dikemukakan pula oleh Atmoko (2010), menjelaskan bahwa: "Standar Operasional Prosedur (SOP) merupakan suatu pedoman atau acuan untuk melaksanakan tugas pekerjaan sesuai denga fungsi dan alat penilaian kinerja instansi pemerintah berdasarkan indikator-indikator teknis, administratif dan prosedural sesuai tata kerja, prosedur kerja dan sistem kerja pada unit kerja yang bersangkutan". Sedangkan menurut Moekijat (2008), Standar Operasional Prosedur (SOP) adalah urutan langkah-langkah (atau pelaksanaan-pelaksanaan pekerjaan), dimana pekerjaan tersebut dilakukan, bagaimana melakukannya, bilamana melakukannya, di mana melakukannya, dan siapa yang melakukannya.

Berdadarkan pendapat para ahli, dapat disimpulkan bahwa Standard Operational Procedure (SOP) merupakan suatu panduan atau aturan kerja yang digunakan oleh perusahaan termasuk hotel, dalam melaksanakan tugas atau pekerjaan secara konsisten sesuai dengan ketentuan yang telah ditetapkan guna meminimalisir terjadinya kesalahan

Selain itu Indah Puji (2014:30) menyatakan bahwa tujuan Standard Operational Prosedure (SOP) yaitu sebagai acuan dan konsistensi kinerja dalam pelaksanaan pekerjaan, menghindari kesalahan dan kegagalam dalam proses pelaksaan kerja, serta sebagai parameter dalam menilai mutu pelayanan.

\section{Metodologi Penelitian}

Dalam artikel ini, jenis penelitian yang digunakan termasuk jenis penelitian deskriptif kualitatif. Menurut Susanto (2015, dalam Wardhana dan Sigit, 2019), "qualitative research is has purposed to describe a process of teaching activity and has the basic what was happened in the field as the study material to finding the weakness and lack of it so it can be the improvement effort, analysis fact, tendency and act of study that happened in the field, arrange the hypothesis that concern to principal and education to data and information that happened in the field".Penelitian ini dilakukan dengan metode wawancara dan dokumentasi dalam pengumpulan datanya.Jenis data yang digunakan dalam penelitian ini adalah menggunakan data kualitatif dengan menggunakan kata-kata untuk menggambarkan fakta dan fenomena yang diamati. Subjek penelitian ini adalah Asst. Manager F\&B Service, Manager, Supervisor, dan Staff Restoran Hotel Berbintang 5 di Bali, tepatnya di Kawasan ITDC Nusa Dua dan Daerah Jimbaran. 


\section{Hasil Penelitian dan Pembahasan}

Keterampilan berbahasa Asing (Bahasa Inggris) dalam dunia Pariwisata sangat penting, mengingat Bahasa Inggris sebagai bahasa internasional. Dimana dalam proses berkomunikasi kita harus mampu menciptakan komunikasi 2 arah antara tamu dan pramusaji. Secara harafiah, menurut Tarigan (2015:2) ada 4 jenis keterampilan berbahasa yang harus dikuasai oleh seorang pramusaji, diantaranya Speaking, Listening, Writing dan Reading. Melalui proses wawancara yang dilakukan oleh penulis dengan narasumber, didapat dari ke-empat keterampilan berbahasa, dua diataranya menjadi hal yang paling penting yang benar-benar harus dikuasi bagi seorang pramusaji, yaitu speaking dan listening. Speaking adalah suatu keterampilan dalam berbicara dengan baik dan tepat. contohnya seperti seorang pramusaji yang akan menjelaskan menu yang akan ditawarkan kepada tamu dan harus berbicara secara jelas dan mudah dimengerti. Dan Listening adalah suatu keterampilan dalam mendengarkan apa yang diinginkan tamu. Contohnya seperti mendegarkan degan baik, keluhan tamu ketika ada masalah dan juga permintaan tamu ketika ada hal yang diinginkan. Selain itu, dalam proses pelayanan, ketepatan (accuracy) juga menjadi hal penting dalam berkomunikasi, hal ini bertujuan agar informasi yang akan diberikan sampai dengan yang diharapkan, guna terwujudnya komunikasi yang lancar antara pramusaji dan tamu, menghindari terjadinya kesalahpahaman dan menghindari terciptanya keluhan dah hal yang tidak diinginkan. Dalam proses komunikasi, grammar dan kelancaran menjadi 2 hal yang tidak dapat dipisahkan mengingat dengan penggunaan grammar yang baik dan benar, yang disertai dengan menguasai banyak kosa kata akan mampu menciptakan komunikasi yang lancar dan tepat.

Selain keterampilan berbahasa penggunaan fungsi dan ekspresi bahasa juga mempengaruhi terjalinya komunikasi. Menurut Halliday dan Hassan (dalam Sulasmini dan Astina, 2018:4) mendefinisikan fungsi bahasa sebagai cara dalam berkata, menulis, membaca, dan mendengar untuk mencapai target tujuan. Dalam hal ini, fungsi bahasa dapat dikaitkan dengan pelaksaan sequence of service di restoran. Dimana, pelaksaan sequence of service di masing-masing restoran berbintang 5 di Bali itu berbeda. Setelah dilakukannya wawancara deangan narasumber di hotel berbintang 5 di Kawasan ITDC Nusa Dua dan Daerah Jimbaran, dapat disimpulkan ada 8 sequences yang harus di lakukan agar terciptanya pelayanan yang baik di mata tamu yaitu sebagai berikut.

Secara keseluruhan, ke-8 point di bawah ini merupakan hal yang wajib dilakukan dalam proses pelayanan tamu di restoran. Adapun hal yang disarankan dan tidak disarankan untuk dilakukan dalam penggunaan fungsi dan ekspresi bahasa saat berkomunikasi dengan tamu yaitu: penggunaan kata-kata seperti (maybe, well, so, ok) tidak disarankan karena mengandung arti informal dan tidak professional, dan disarankan menggunakan kata (please, if you don't mind, certainly) karena terdengar lebih professional dan sopan. Selain itu penggunaan kata "Want 
diganti menjadi would/ may", "Can diganti menjadi could", "your welcome diganti menjadi my pleasure", dan "Sorry diganti menjadi apologize".

Dalam kaitannya dengan proses komunikasi dalam memberikan pelayanan komunikasi verbal dan nonverbal juga merupakan hal yang sangat penting, hal ini karena proses komunikasi yang terjalin akan mempengaruhi pelayanan yang akan diterima tamu. Mengingat komunikasi verbal merupakan komunikasi langsung yang terjalin dengan tamu menggunakan bahasa yang baik sopan dan tepat dan komunikasi nonverbal, berupa komunikasi melalui bahasa tubuh (Kusumawati, 2016).Adapun etika yang harus di perhatikan yaitu mengenai hal yang disarankan dan tidak disarankan dalam proses komunikasi yaitu; nooding, show some respect with full hand instead of we use our finger, smile and use eye contact, dan hal yang tidak disarankan untuk dilakukan yaitu; menggunakan jari untuk mengisyaratkan OK, mengedipkan mata, penggunaan kata kasar, mengerutkan alis, bibir yang mengerucut, melihat kearah lain ketika berkomunikasi dengan tamu dan berbicara dengan tim ketika berhadapan dengan tamu.

Tabel 1. Fungsi dan Ekspresi Bahasa sesuai pelaksanaan Sequence of Service (SOS)

\begin{tabular}{|c|c|c|c|}
\hline No. & $\begin{array}{l}\text { Fungsi } \\
\text { Bahasa }\end{array}$ & Ekspresi Bahasa & Keterangan \\
\hline 1 & $\begin{array}{l}\text { Greeting and } \\
\text { acknowledge } \\
\text { guest }\end{array}$ & $\begin{array}{l}\text { "Good afternoon, } \\
\text { welcome to our } \\
\text { restaurant, how are } \\
\text { you today?" } \\
\text { "May I have your } \\
\text { reservation name } \\
\text { and your room } \\
\text { number?" }\end{array}$ & $\begin{array}{l}\text { Senyum yang tulus dan } \\
\text { handgestures. }\end{array}$ \\
\hline 2 & $\begin{array}{l}\text { Escorting the } \\
\text { Guest }\end{array}$ & $\begin{array}{l}\text { "I will escort you to } \\
\text { get your table" }\end{array}$ & $\begin{array}{l}\text { Senyum, mengarahkan, dan } \\
\text { mempersilakan tamu duduk. }\end{array}$ \\
\hline 3 & $\begin{array}{l}\text { Present } \\
\text { menu and } \\
\text { highlight } \\
\text { special menu } \\
\text { of the day }\end{array}$ & $\begin{array}{l}\text { "Please take a look } \\
\text { our menu and I would } \\
\text { like to inform you our } \\
\text { special of the day, } \\
\text { please take your time } \\
\text { and let us know if } \\
\text { there any question" }\end{array}$ & $\begin{array}{l}\text { Senyum dan show some } \\
\text { respect with full hand instead of } \\
\text { we are use our finger }\end{array}$ \\
\hline 4 & $\begin{array}{l}\text { Take the } \\
\text { order }\end{array}$ & $\begin{array}{l}\text { "Alright Sir/Madan. } \\
\text { Could you pay } \\
\text { attention for a minute, } \\
\text { I would like to repeat } \\
\text { your order ......." }\end{array}$ & $\begin{array}{l}\text { Untuk poinini harus di garis } \\
\text { bawahi untuk mengurangi } \\
\text { penggunaan kata "order" } \\
\text { karena tugas seorang } \\
\text { pramusaji adalah untuk } \\
\text { menjual dan membantu tamu } \\
\text { dalam memberikan } \\
\text { rekomendasi ke tamu bukan } \\
\text { menunggu sampai tamu angkat } \\
\text { tangan (ready to order). }\end{array}$ \\
\hline 5 & $\begin{array}{l}\text { Serve } \\
\text { food }\end{array}$ & $\begin{array}{l}\text { "Excuse me, this is } \\
\text { medium steak frittes } \\
\text { with chimicuri sauce } \\
\text { and Asian coslow on } \\
\text { top, please enjoy } \\
\text { your food" }\end{array}$ & $\begin{array}{l}\text { Senyum dan mengangguk } \\
\text { (mempersilakan makan). }\end{array}$ \\
\hline
\end{tabular}




\begin{tabular}{|c|c|c|c|}
\hline No. & $\begin{array}{l}\text { Fungsi } \\
\text { Bahasa }\end{array}$ & Ekspresi Bahasa & Keterangan \\
\hline 6 & $\begin{array}{l}\text { Quality } \\
\text { assurance }\end{array}$ & $\begin{array}{l}\text { "How is the food?" } \\
\text { "Excuse me } \\
\text { Sir/Madam, Could I } \\
\text { take/clear this .... } \\
\text { (empty } \\
\text { stuff/plate/glass) }\end{array}$ & $\begin{array}{l}\text { Untuk poin ini, bisa ditanyakan } \\
\text { juga feedback dari tamu } \\
\text { apakah ada yang kurang atau } \\
\text { mungkin over cooked, } \\
\text { sehingga kita bisa buatkan } \\
\text { makanan yang baru karena } \\
\text { balik lagi, kepuasan tamu } \\
\text { adalah nomor satu. }\end{array}$ \\
\hline 7 & $\begin{array}{l}\text { Offer after } \\
\text { dinner drinks }\end{array}$ & $\begin{array}{l}\text { "would you like to } \\
\text { have some espresso } \\
\text { martini or a cup of hot } \\
\text { coffee" }\end{array}$ & $\begin{array}{l}\text { Untuk poin ini bisa dilakukan } \\
\text { untuk lunch time juga, karena } \\
\text { after dinner drink tidak hanya } \\
\text { berlaku saat dinner saja. } \\
\text { Biasanya dilakukan bersamaan } \\
\text { dengan dessert order atau } \\
\text { tanpa dessert order. }\end{array}$ \\
\hline 8 & $\begin{array}{l}\text { Billing and } \\
\text { bid farewell }\end{array}$ & $\begin{array}{l}\text { "Excuse me, please } \\
\text { double check you bill } \\
\text { carefully" } \\
\text { "Shall I call you a } \\
\text { taxi?" } \\
\text { "Saying thank you or } \\
\text { good bye" }\end{array}$ & $\begin{array}{l}\text { Senyum dan handgestures } \\
\text { Balinese style. }\end{array}$ \\
\hline
\end{tabular}

Sumber: Hasil olah data penulis 2020

\section{Penutup}

Berdasarkan uraian mengenai Analisis Kebutuhan Bahasa Inggris Pramusaji di Hotel Berbintang 5 di Bali dapat disimpulkan bahwa dari keempat keterampilan berbahasa (Speaking, Listening, Writing dan Reading), Speaking \& Listening skill merupakan poin utama yang wajib dikuasai oleh seorang pramusaji, serta terkait dengan ketepatan (accurancy) grammar dan kelancaran (fluency) dalam berkomunikasi memegang peranan yang sama penting, mengenai fungsi dan ekspresi bahasa yang dibutuhkan oleh seorang pramusaji yaitu Ekspresi bahasa yang digunakan menyesuaikan dengan fungsi bahasa yang telah ditetapkan berdasarkan pelaksanaan Squence of Service (SOS) di restoran. Selain menguasai fungsi dan ekspresi bahasa, etika dalam berkomunikasi secara verbal dan nonverbal juga merupakan hal yang sangat penting karena mempengaruhi kesuksesan dalam berkomunikasi.

Penelitian hanya terbatas pada suatu daerah di Bali dengan ruang lingkup yang lebih kecil, mengingat penelitian ini hanya dilakukan pada 4 hotel berbintang 5 di Bali. Maka penelitian ini perlu dilakukannya penelitian lanjut.

Responden pada penelitian ini sangat terbatas, mengingat kondisi Pandemi COVID-19 ini membuat penulis tidak dapat melaksanakan wawancara lebih mendalam, dalam ruang lingkup yang lebih luas mengenai kebutuhan bahasa inggris bagi pramusaji di hotel berbintang 5 di bali. 
Besar harapan penulis nantinya penelitian mengenai Analisa kebutuhan Bahasa Inggris bagi Pramusaji di Hotel Berbintang 5 di Bali ini bisa dilanjutkan dengan ruang lingkup yang lebih luas.

\section{Daftar Pustaka}

Alfiriani, Adlia., dkk.2017.Analisis Kebutuhan Belajar Mahasiswa Pada Mata Kuliah Strategi PembelajaranTI. Sumatera Barat : Program Studi Pendidikan Informatika, STKIP PGRI Sumatera Barat.

AS, Fitria Earlike dan Atalina, Tutut Mega Mukti. 2016. Pentingnya peranan skill dan menu knowledge waiter/waiters terhadap kepuasan pelanggan di food and beverage service department. Malang: Program Diploma Kepariwisataan Universitas Merdeka Malang.

Damayanti, Luh Sri. 2019. Peranan Keterampilan Berbahasa Inggris Dalam Industri Pariwisata. Bali: Politeknik Internasional Bali.

Fernandez, Inyo Yos. 2008. Kategori Dan Ekspresi Linguistik Dalam Bahasa Jawa Sebagai Cermin Kearifan Lokal Penuturnya: Kajian Etnolinguistik Pada Masyarakat Petani Dan Nelayan. Yogyakarta: UGM.

Guntur dan Yulianto. 2015. Upaya profesionalisme kerja waiter untuk peningkatan pelayanan tamu di the grand palace hotelyogyakarta. Yogyakarta: AKPAR BSI Yogyakarta.

Juita, Mentari Danny. 2017. Kualitas Pelayanan Pramusaji Di Cinnamon Poolside Restaurant Hotel D`Oxville Padang. Padang: UNP

Kusumawati, Tri Indah. 2016. Komunikasi Verbal Dan Nonverbal. Jurnal Pendidikan dan Konseling.Medan: UIN Sumatra Utara.

Mahardika. 2019. Analisis Kebutuhan Fungsi Dan Expresi Bahasa Untuk Resepsionis Di Hotel Berbintang Di Bali. Bali: UNDIKSHA.

Mahfud, Tuatul, dkk., 2017. Peta Kompetensi Soft Skill Program Pemagangan (Apprenticeship Programe) di Industri Perhotelan Balikpapan. Balikpapan: Universitas Negeri Balikpapan.

Manis, Si. 2019. Standar Operasional Prosedur (SOP). Pelajaran.co.id.

Puspitasari. 2013. English For Computer Science: Sebuah Analisis Kebutuhan Bahasa Inggris Pada Mahasiswa Teknik Informatika. Jurnal Pro Bisnis.Purwokerto: STIMIK AMIKOM Purwokerto.

Redjasa, IK. 2014. Peranan Tata Hidangan Dalam Menumbuhkembangkan Industri Pariwisata Di Era Globalisasi. Bali: Politeknin Negeri Bali.

Rosandya, Rindy. 2017. Indonesia Masih Kekurangan Tenaga Kerja Terampil. Harian Ekonomi Neraca.

Prastya, Ilham. 2020. Pengertian Keterampilan Menurut Para Ahli dan Keterampilan Yang Dibutuhkan Dalam Dunia Kerja Saat Ini. Ayoksinau.com. 
Sulasmini dan Astina (2018). Identifikasi Fungsi Bahasa Yang Berbasiskan Kearifan Lokal Pada Materi Pembelajaran Bahasa Inggris Perhotelan Bidang Tata Hidang. Bali: STPBI.

Suardana dan Nurhayati. 2019. Kinerja Waiter/Waitress Dalam Upaya Meningkatkan Kualitas Pelayanan (Studi Kasus Di Hotel Sahid Raya Yogyakarta). Yogyakarta: AKPARDA

Utama, Ida Bagus Rai. 2014. Pengantar Industri Pariwisata. Yogyakarta. Deeppublish.

Wahyuningsih, Sri. 2019. Pengaruh Tenaga Tata Hidang Pariwisata Terhadap Kualitas Pelayanan Di Hotel. Mataram: STP Mataram.

Wardhana dan Sigit (2019. English Language Needs Of Restaurant Waiters \& Bars At Mama's German Restaurant: Target Situation Analysis. Bali: Dyana Pura University. 